\title{
Generation and Characterization of an Atmospheric-Pressure Plasma Jet (APPJ) and Its Application in the Surface Modification of Polyethylene Terephthalate
}

\author{
Hom Bahadur Baniya $\mathbb{D}^{1,2}$ Rajendra Shrestha, ${ }^{3}$ Rajesh Prakash Guragain $\mathbb{D},{ }^{1}$ \\ Mohan Bahadur Kshetri, ${ }^{4}$ Bishnu Prasad Pandey $\mathbb{D}^{5},{ }^{5}$ and Deepak Prasad Subedi ${ }^{1}$ \\ ${ }^{1}$ Department of Physics, School of Science, Kathmandu University, Kavre, Nepal \\ ${ }^{2}$ Department of Physics, Trichandra College, Tribhuvan University, Kathmandu, Nepal \\ ${ }^{3}$ Department of Science and Humanities, Nepal Banepa Polytechnic Institute (CTEVT), Nepal \\ ${ }^{4}$ Department of Physics, Amrit Science College, Tribhuvan University, Kathmandu, Nepal \\ ${ }^{5}$ Department of Chemical Science and Engineering, Kathmandu University, Kavre, Nepal \\ Correspondence should be addressed to Hom Bahadur Baniya; hom.baniya@student.ku.edu.np \\ and Rajesh Prakash Guragain; rayessprakash@gmail.com
}

Received 16 September 2019; Revised 14 January 2020; Accepted 23 January 2020; Published 11 February 2020

Academic Editor: Cornelia Vasile

Copyright (C) 2020 Hom Bahadur Baniya et al. This is an open access article distributed under the Creative Commons Attribution License, which permits unrestricted use, distribution, and reproduction in any medium, provided the original work is properly cited.

\begin{abstract}
An atmospheric-pressure plasma jet (APPJ) has a lot of applications in recent years such as in material processing, surface modification, biomedical material processing, and thin film deposition. APPJ has been generated by a high-voltage power supply $(0-20 \mathrm{kV})$ at an operating frequency of $27 \mathrm{kHz}$. This paper reports the generation and characterization of APPJ in argon environment and its application in the surface modification of polyethylene terephthalate (PET). The plasma jet has been characterized by electrical and optical methods. In order to characterize the plasma jet, electron density and electron temperature have been determined. The surface roughness of the untreated and plasma-treated PET samples was characterized by contact angle measurement, surface energy analysis, Fourier transform infrared (FTIR) spectroscopy, scanning electron microscopy (SEM), and atomic force microscopy (AFM).
\end{abstract}

\section{Introduction}

Nonthermal and low-temperature plasma has become a subject of great interest. Till now, different types of low-pressure systems and few atmospheric-pressure systems have been developed. Low-pressure plasma sources have been used for polymer surface treatment, cleaning of substrates, and deposition of thin films. Various applications of nonthermal plasma have been extensively investigated nowadays $[1,2]$. The discharge produced in atmospheric pressure is also stable even at low frequency as compared to RF sources which are much more expensive. By working under gas conditions, the active species can be blown out of the reactor to form a luminous plasma jet with moderate energy density in the open air, thus fascinating its applications in material process- ing, biomedicine, and thin film deposition [3, 4]. Plasma consists of ions, free electrons, free radicals, excited species, photons, and neutrals [5]. One of the important areas of application of atmospheric-pressure plasma is in the surface treatment of polymers to improve their hydrophilicity. This application is motivated due to many advantages over the conventional method of surface treatment $[6,7]$. Polymers are generally macromolecules formed by the repeated linking of a large number of small molecules [8]. Polymers which play an increasing role as structural materials are widely used in industries in recent years $[9,10]$. Polymers are attractive business articles due to their superior performance, low cost, good breakage resistance, transparency, and low inflammability. However, its low hardness, low scratch resistance, and degradation by UV radiation made surface modification 

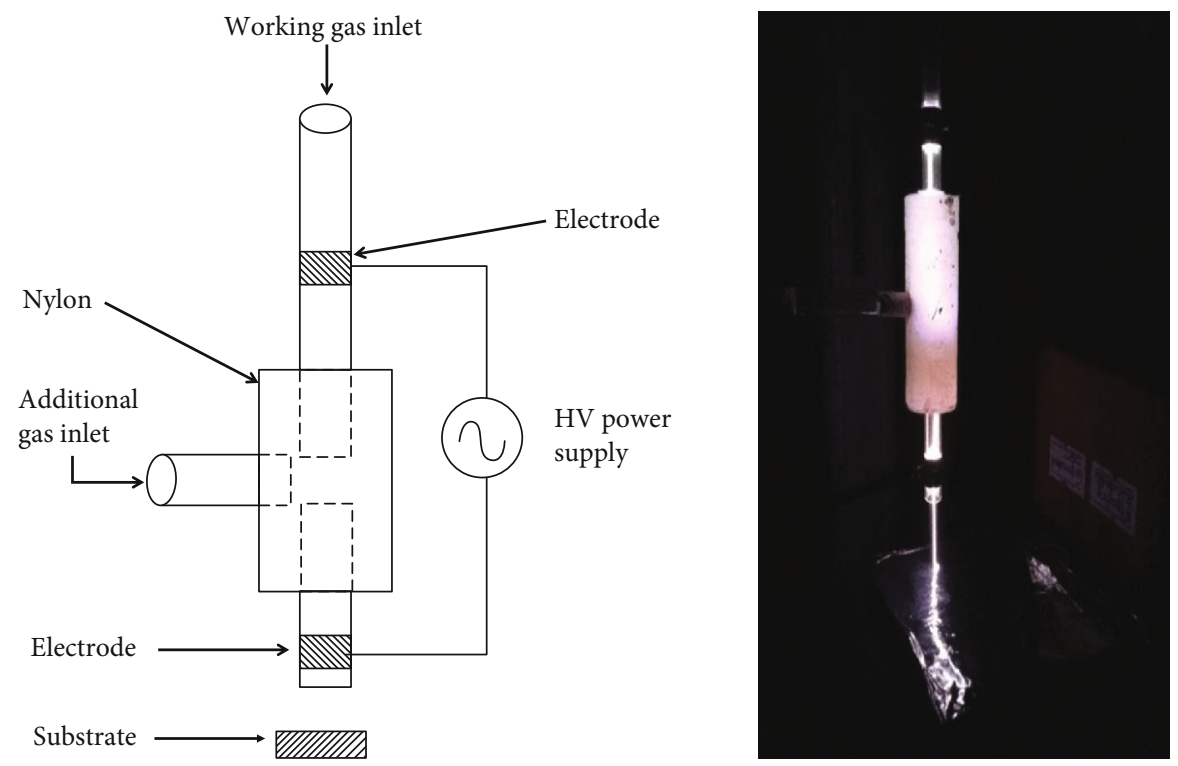

FIGURE 1: Schematic diagram of the experimental setup and image of the discharge.

necessary $[11,12]$. Because of their low surface energy, poor chemical reactivity, and weak cohesion layer on the surface, it is necessary to improve the surface properties of polymers without changing the bulk properties $[13,14]$. PET, being an inert material, is widely accepted as a safe and recyclable plastic which is one of the reasons why it is so commonly used in beverage packaging, electronics, and biomedical industries. Similar to glass, it is hygienic and generally resistant to attack by bacteria and other microorganisms [15]. Previous works on APPJ use a single glass tube for the generation of the jet which makes it inconvenient to introduce any additional working gases or precursor materials in the discharge regime [16]. However, in the present setup, three tubes are coupled with a nylon (Teflon) coupler which facilitates the introduction of an additional inlet for gases in the discharge regime without any detriment to the jet formation mechanism. Moreover, most of the previous works have used an RF power supply which is more expensive compared to the power supply used in the present study.

\section{Materials and Methods}

The reactor was designed and fabricated at the Kathmandu University Plasma Physics laboratory. The experimental setup consists of a capacitively coupled electrode system made of copper foil of thickness $1 \mathrm{~mm}$ wrapped around two borosilicate glass tubes of outer diameter $6 \mathrm{~mm}$ and inner diameter $5 \mathrm{~mm}$. The copper electrode is connected to a high-voltage power supply, and the glass tube is coupled with a nylon (Teflon) coupler of length $49 \mathrm{~mm}$. The distance between two electrodes is fixed at $80 \mathrm{~mm}$, and the distance between the tip of the nozzle and the lower electrode is $3 \mathrm{~mm}$. The system consists of one additional gas inlet with a third tube connected with a nylon coupler horizontally in the middle. This third tube can be used to introduce additional gas into the system. Argon is used as a working gas in the experiment. The schematic diagram of the experimental setup and the nature of the discharge is shown in Figure 1. The flow rate for argon gas is $2 \mathrm{~L} / \mathrm{min}$, and the voltage and frequency are maintained at $4.5 \mathrm{kV}$ and $27 \mathrm{kHz}$, respectively. The electrical characterization of the discharge is done by the measurement of current and voltage waveforms using a Tektronix TDS2002 oscilloscope by a current probe and high voltage probe (PINTEK HVP-28HF). The attenuation ratio of the voltage probe is $1000: 1$. Similarly, optical characterization of the discharge has been done using the line intensity ratio method with the help of an optical emission spectrometer (USB 2000+, Ocean Optics). The contact angle of the untreated and plasmatreated PET samples is measured using the Rame Hart contact angle goniometer (Model 200). The ATR-FTIR spectroscopy measurements of PET foils were performed with the PerkinElmer Spectrum 100 FTIR spectrometer fitted with a Universal Attenuated Total Reflectance (UATR) polarization accessory in the spectral range of $4000-500 \mathrm{~cm}^{-1}$ at the resolution of $4 \mathrm{~cm}^{-1}$ for 20 accumulations per analysis. Before the treatment, the samples of dimensions $(50 \mathrm{~mm} \times 15 \mathrm{~mm} \times 0.05 \mathrm{~mm})$ were taken. The samples were provided by Goodfellow, UK. Before treatment, removal of organic contaminants from the surface of the specimens was done by rinsing in isopropyl alcohol for 10 minutes. The samples were then ultrasonically cleaned in distilled water for 20 minutes and after that dried at room temperature. All plasma treatments were carried out in argon at atmospheric pressure and ambient temperature. The contact angle measurement was done at five different locations of the same samples, and the average value of the contact angle thus obtained was used for the surface energy calculations. In this work, an LEO (500)/Zeiss field-emission scanning electron microscope (SEM) was used to examine surface morphology. A Multimode 8 Nanoscope atomic force microscope (AFM, Bruker, USA) was used to image the surfaces of the nonmodified substrate and plasma-treated films of PET. Silicon cantilevers with a spring constant of ca. $0.5 \mathrm{Nm}^{-1}$ (HQ:NSC19/No Al type; MikroMasch, Bulgaria) were applied for imaging in PeakForce Tapping ${ }^{\mathrm{TM}}$ Force Microscopy Mode. 


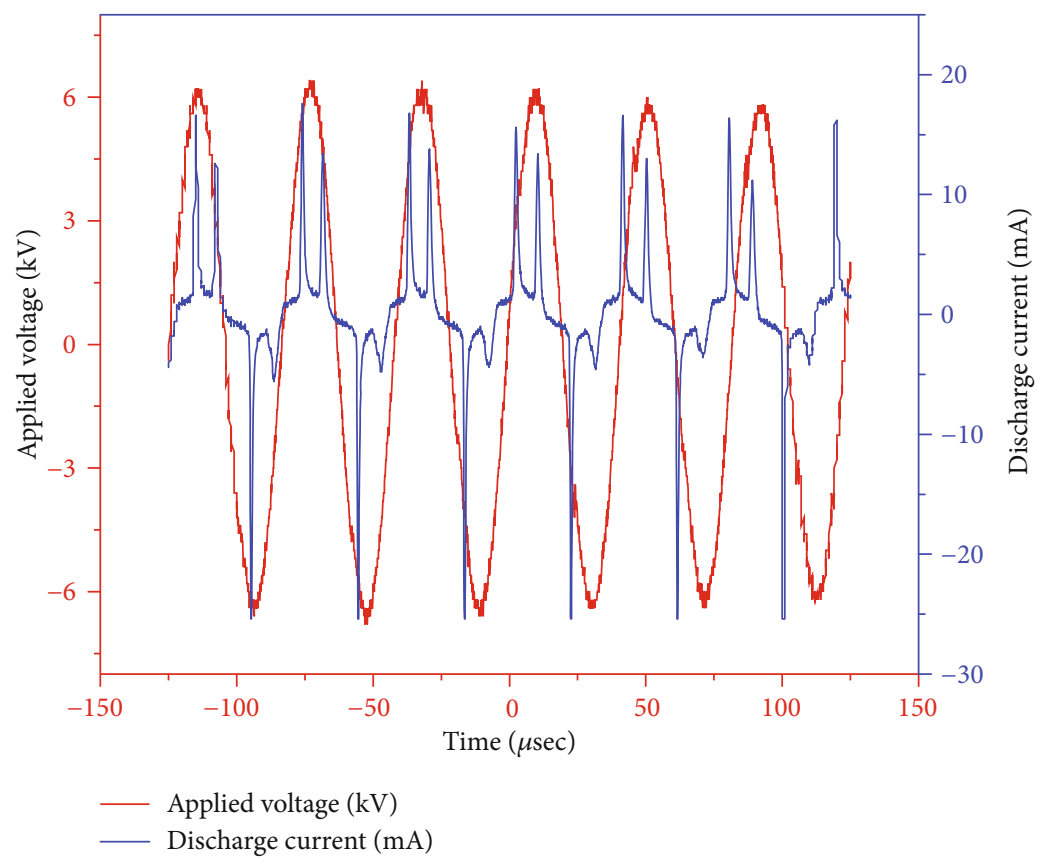

Figure 2: Current voltage graph at gas flow rate $(Q)=2 \mathrm{~L} / \mathrm{min}$ at an applied voltage of $4.5 \mathrm{kV}$.

The microscope was calibrated by the imaging of calibration gratings supplied by the manufacturer.

\section{Results and Discussions}

3.1. Electrical Characterization of the Discharge. Figure 2 shows the applied voltage and discharge current waveforms obtained in APPJ with electrode distance $80 \mathrm{~mm}$, applied voltage $4.5 \mathrm{kV}$, and resistance $10 \mathrm{k} \Omega$. Electron density can be estimated from the measured value of current density according to the relation [17].

$$
n_{\mathrm{e}}=\frac{J}{\mu e E} .
$$

For the electron mobility, we use $\mu=302 \mathrm{~cm}^{2} \mathrm{~V}^{-1} \mathrm{~S}^{-1}$ the strength of the electric field, $E=5.625 \times 10^{2} \mathrm{~V} \mathrm{~cm}^{-1}$. Substituting this value in Equation (1), the electron density was found to be $2.25 \times 10^{15} \mathrm{~cm}^{-3}$.

3.2. Optical Characterization of the Discharge. Figure 3 shows the spectra of the discharge and their corresponding intensities and wavelength using argon as a working gas. The optical characterization of the discharge was carried out by using the line intensity ratio method. In this method, four suitable lines (two for Ar I and two for Ar II) were chosen from spectral lines of argon obtained from the discharge. The working formula used to calculate the electron temperature is as follows $[18,19]$.

$$
\begin{aligned}
\frac{R_{1}}{R_{2}}= & \frac{I_{1} / I_{2}}{I_{3} / I_{4}}=\left(\frac{A_{p q}}{A_{r s}}\right)\left(\frac{g_{p}}{g_{r}}\right)\left(\frac{\lambda_{r s}}{\lambda_{p q}}\right)\left(\frac{A_{u v}}{A_{x y}}\right)\left(\frac{g_{u}}{g_{x}}\right) \\
& \cdot\left(\frac{\lambda_{x y}}{\lambda_{u v}}\right) \exp \left[-\frac{E_{p}-E_{r}-E_{x}+E_{v}}{K_{\mathrm{B}} T_{\mathrm{e}}}\right] .
\end{aligned}
$$

Here, in Equation (2), $R$ is the ratio of the intensity of two lines, $I$ is the intensity of the spectral line, $A_{j i}$ is the transition probability of the transition $i \rightarrow j, g_{i}$ is the statistical weight of the upper level, $\lambda$ is the wavelength of the line radiation, $E_{i}$ is the energy of the upper level, $K_{\mathrm{B}}$ is the Boltzmann constant, and $T_{\mathrm{e}}$ is the electron temperature. The values of $\lambda$ and $I$ are obtained from the observation, and the values of $A_{j i}, g_{i}$, and $E_{i}$ are obtained from the National Institute of Standards and Technology (NIST) Atomic Spectra Database.

The corresponding values of the transition probability, statistical weight, and energy levels for the argon I and II lines were obtained through the NIST database [20].

Table 1 shows the corresponding value of the ratio of the intensity of the spectral lines $\left(R_{1} / R_{2}\right)$ with change in electron temperature $\left(T_{\mathrm{e}}\right)$.

From Figure 4, the electron temperature $\left(T_{\mathrm{e}}\right)$ was found to be $0.551 \mathrm{eV}$.

Also, the electron density was calculated by using

$$
\begin{aligned}
n_{\mathrm{e}}= & 2\left(\frac{I_{1}}{I_{2}}\right)\left(\frac{\lambda_{p q}}{\lambda_{x y}}\right)\left(\frac{A_{x y}}{A_{p q}}\right)\left(\frac{g_{x}}{g_{p}}\right) \\
& \cdot\left(\frac{2 \pi m_{e} K_{\mathrm{B}} T_{\mathrm{e}}}{h^{2}}\right)^{3 / 2} \exp \left(-\frac{E_{i}+E_{p}-E_{x}}{K_{\mathrm{B}} T_{\mathrm{e}}}\right) .
\end{aligned}
$$

Hence, the electron density was found to be about $n_{\mathrm{e}}=$ $2.116 \times 10^{16} \mathrm{~cm}^{-3}$.

\subsection{Surface Modification of Polyethylene Terephthalate (PET)}

3.3.1. Contact Angle and Surface Energy Measurements. For an ideal, smooth, and homogeneous surface, the water contact angle and surface free energy are measured at the 

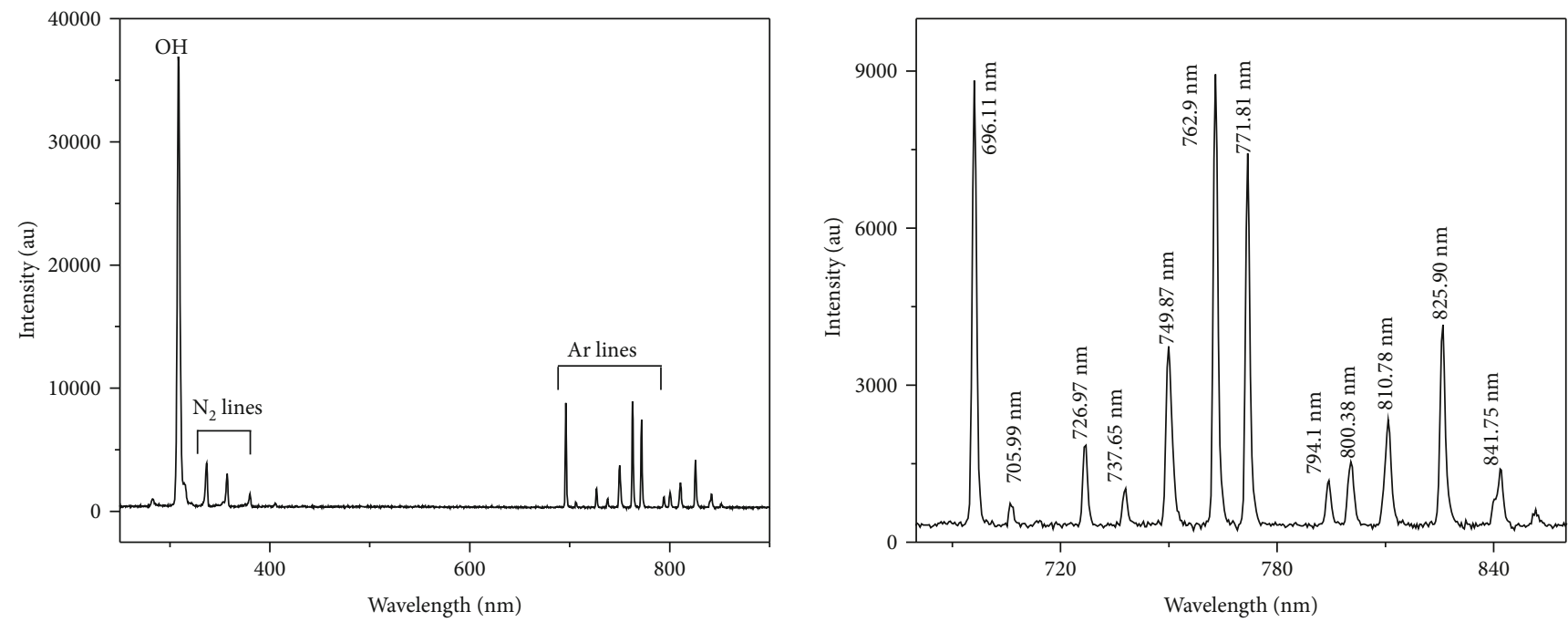

FIGURE 3: Spectra of the discharge at a frequency of $27 \mathrm{kHz}$ and an applied voltage of $4.5 \mathrm{kV}$ in argon environment (gas flow rate $(Q)=2 \mathrm{~L} / \mathrm{min}$ ).

TABLE 1: Electron temperature and its corresponding intensity ratio.

\begin{tabular}{lc}
\hline Electron temperature $\left(T_{\mathrm{e}}\right)$ & $\begin{array}{c}\text { Ratio of the intensity of } \\
\text { spectral lines }\left(R_{1} / R_{2}\right)\end{array}$ \\
\hline 0.5 & 1.7751 \\
0.6 & 1.76531 \\
0.7 & 0.41961 \\
0.8 & 0.26736 \\
0.9 & 0.1883 \\
1.0 & 0.14225 \\
1.1 & 0.11309 \\
1.2 & 0.09341 \\
1.3 & 0.07945 \\
1.4 & 0.06916 \\
1.5 & 0.06133 \\
\hline
\end{tabular}

equilibrium according to Young's equation and OwensWendt-Kaelble methods, respectively [21].

$$
\cos \theta=\frac{\gamma_{\mathrm{sv}}-\gamma_{\mathrm{sl}}}{\gamma_{\mathrm{lv}}},
$$

where $\gamma_{\mathrm{sv}}$ is the surface free energy of the solid substrate, $\gamma_{\mathrm{sl}}$ is the interfacial tension between the solid and the liquid, and $\gamma_{\mathrm{l}}$ is the surface tension of the liquid.

For two liquids $i$ and $j$,

$$
\begin{aligned}
& \gamma_{l i}\left(1+\cos \theta_{i}\right)=2\left(\gamma_{l i}^{\mathrm{d}} \gamma_{\mathrm{s}}^{\mathrm{d}}\right)^{1 / 2}+2\left(\gamma_{\mathrm{li}}^{\mathrm{p}} \gamma_{\mathrm{s}}^{\mathrm{p}}\right)^{1 / 2} \\
& \gamma_{\mathrm{lj}}\left(1+\cos \theta_{j}\right)=2\left(\gamma_{\mathrm{lj}}^{\mathrm{d}} \gamma_{\mathrm{s}}^{\mathrm{d}}\right)^{1 / 2}+2\left(\gamma_{\mathrm{lj}}^{\mathrm{p}} \gamma_{\mathrm{s}}^{\mathrm{p}}\right)^{1 / 2} .
\end{aligned}
$$

Putting the known values of the surface tension and its polar and dispersion components of the test liquids, compo- nents of surface free energy of the solid $\gamma_{\mathrm{s}}^{\mathrm{p}}$ and $\gamma_{\mathrm{s}}^{\mathrm{d}}$ can be determined by solving Equations (5) and (6). The sum of these two quantities eventually gives the total surface energy of the solid [22].

The treatment of the sample was performed for various exposure times (10-120 seconds). The influence of this parameter on the hydrophilicity was investigated by contact angle measurement using two test liquids (water and glycerol) on the surface. It is seen that a rapid decrease in the static water contact angle takes place with the treatment time up to 10 seconds which shows an increase in wettability in the surface induced by APPJ treatment. Initially, the contact angle of the untreated PET for water and glycerol was $82^{\circ}$ and $88^{\circ}$, but after plasma treatment, the contact angle was effectively reduced to $26^{\circ}$ and $30^{\circ}$, respectively, and became almost constant after the treatment time 50 seconds as shown in Figure 5. The reduction in the contact angle might be due to the change in the surface roughness as seen from SEM and AFM micrographs [23].

The variation of surface energy with a polar and dispersive component is shown in Figure 6. Total surface energy increases from $26.1 \mathrm{~mJ} / \mathrm{m}^{2}$ to $64.99 \mathrm{~mJ} / \mathrm{m}^{2}$ during 10 seconds of its treatment time. A similar trend is also observed for the polar component, and it is mainly due to the incorporation of the polar species such as carbonyl $(\mathrm{C}=\mathrm{O})$, hydroxyl $(-\mathrm{OH})$, and carboxyl $(-\mathrm{COOH})$ groups on the treated PET surface. The dispersive component almost remains constant. This component does not have any contribution to increase the wettability [24].

3.4. SEM Images of the Control and Plasma-Treated PET. Figures 7 and 8 show the SEM morphology of the control and plasma-treated surfaces of PET at 60 seconds. The gradual increase in the particle grain size with the image scan area can be realized. SEM images of the control and treated samples clearly indicated that the plasma jet treatment produces a significant increase in roughness on the surface [25]. 


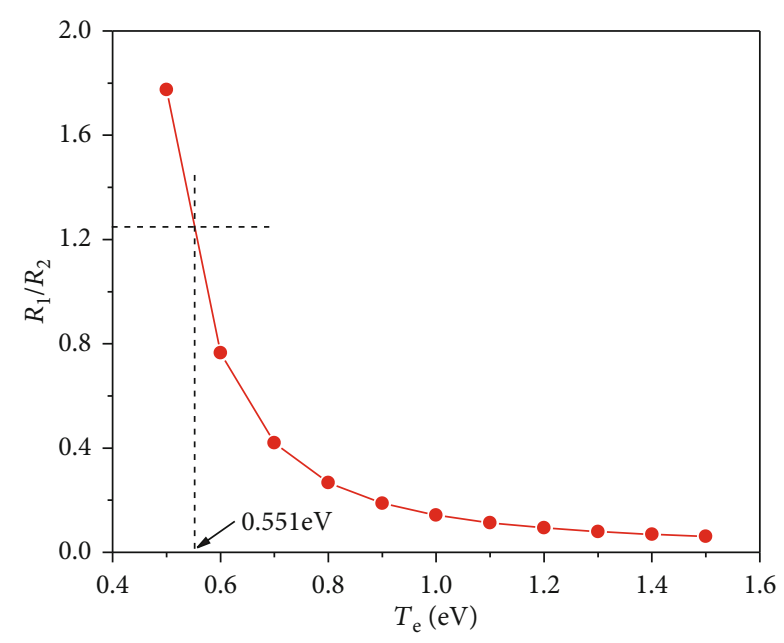

Figure 4: Plot of $R_{1} / R_{2}$ as a function of $T_{\mathrm{e}}$.

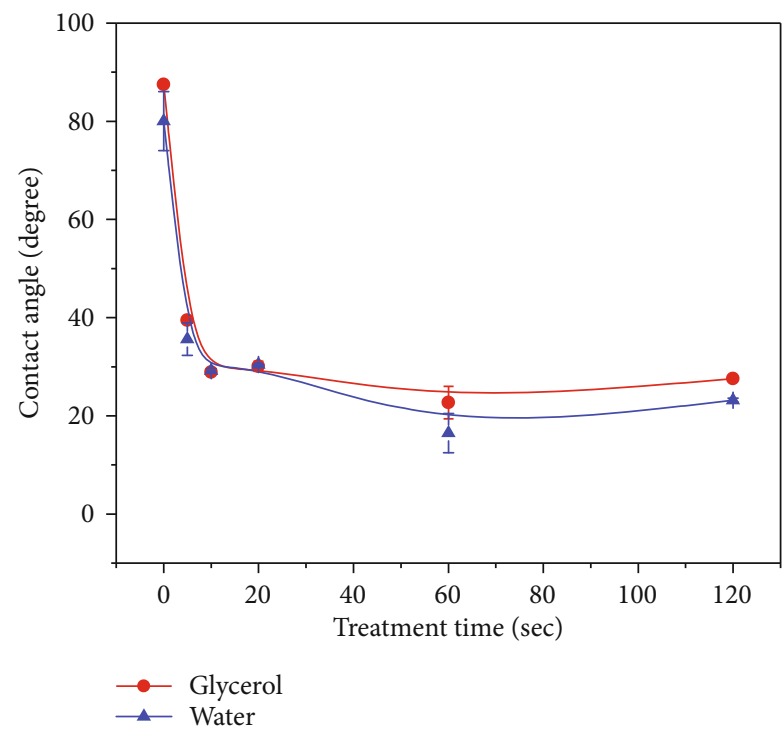

FIGURE 5: Variation of the contact angle as a function of treatment time.

3.5. AFM Images of the Control and Plasma-Treated PET. Figures 9 and 10 show the AFM micrographs of the control and plasma-treated surfaces of PET at 120 seconds. The control surface is relatively smooth, homogeneous, and defectfree, without specific morphological aspects. After the plasma jet treatment, the surface of the PET film showed rough morphology. It can be seen that the surface is etched and the surface roughness is increased. Here, it is seen that the treatment forms numerous uniformly distributed smaller irregular protrusions on the treated surface. These morphological changes may be due to the removal of the top few monolayers of the polymer film, caused by the bombardment of plasma particles on the surface. The change in surface morphology of the sample after treatment was studied by atomic force microscopy (AFM). This resulted in an apparent increase in the surface roughness causing improvement in wettability [26].

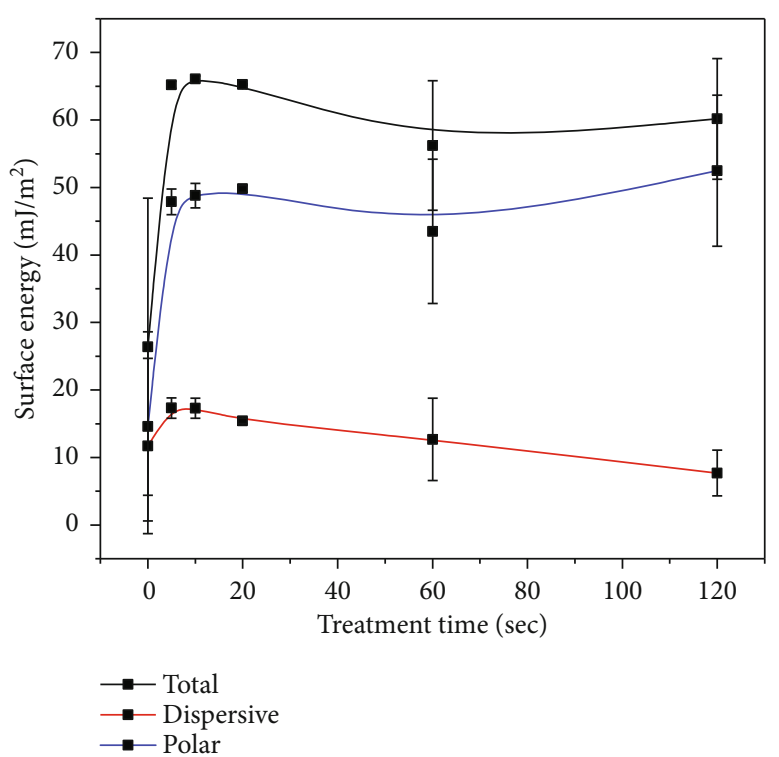

FIGURE 6: Variation of surface free energy as a function of treatment time.

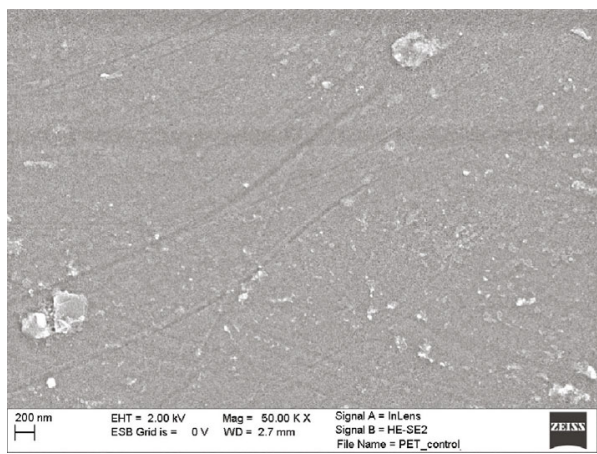

Figure 7: SEM image of the control sample of PET.

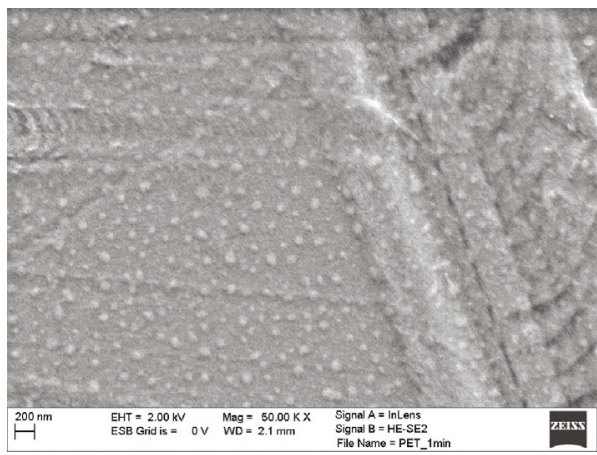

FIgURE 8: SEM image of the plasma-treated sample of PET.

3.6. Fourier Transform Infrared (FTIR) Analysis. Figure 11 shows the FTIR spectra of control and plasma-treated samples at 120 seconds. Chemical changes in surface properties of the plasma-treated polymer were analysed by FTIR spectroscopy. Spectra show that there is change in intensity of absorption peaks of certain functional groups. FTIR analysis 


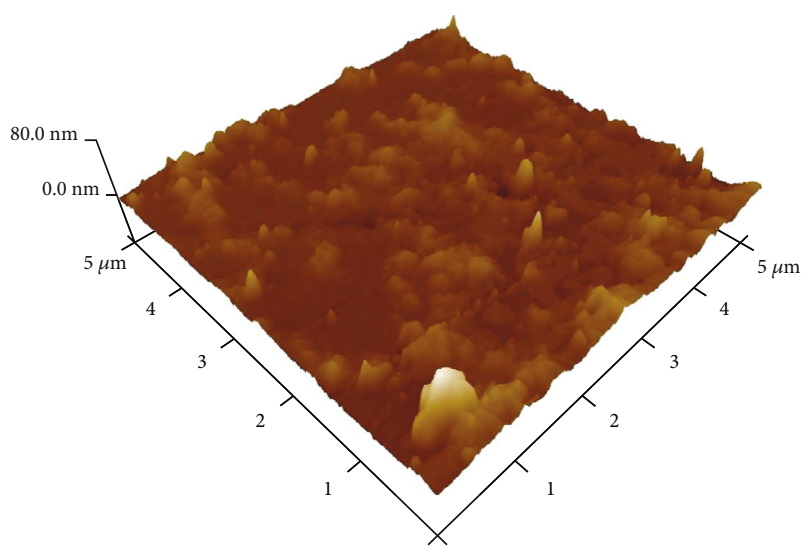

FIGURE 9: AFM image of the control sample of PET.

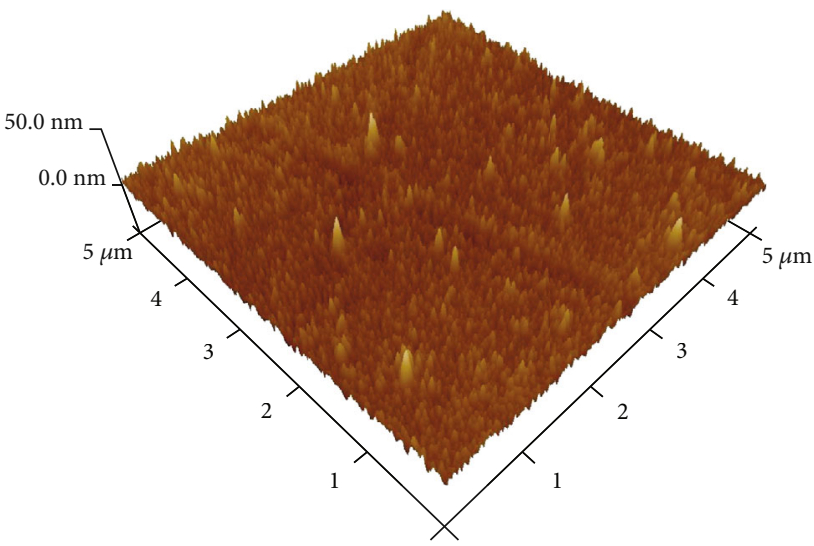

Figure 10: AFM image of the plasma-treated sample of PET.

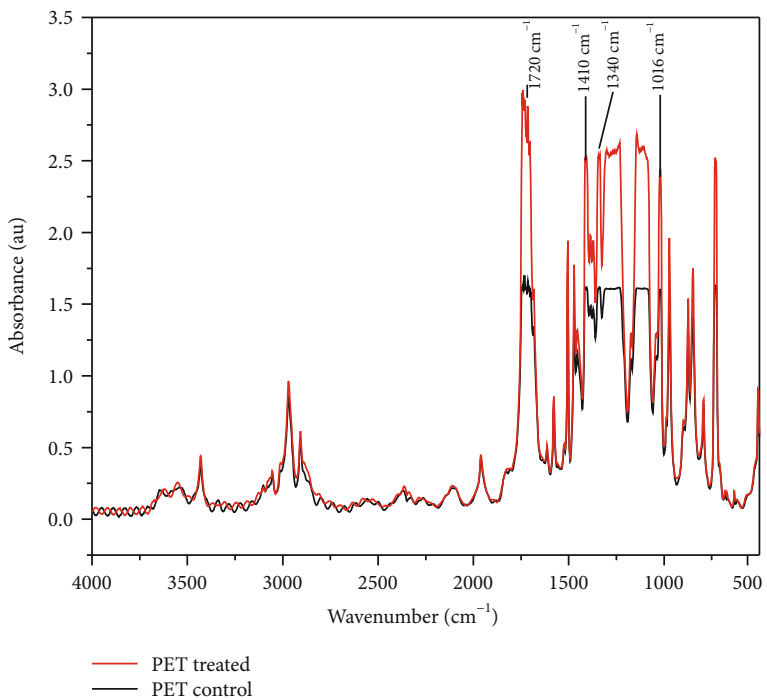

FIGURE 11: ATR-FTIR spectrum of control and plasma-treated PET.

shows aromatic $\mathrm{C}-\mathrm{H}$ wagging at $722.57 \mathrm{~cm}^{-1}$, O-C-C asymmetric stretching peaks at $1096 \mathrm{~cm}^{-1}$, carbonyl $(\mathrm{C}=\mathrm{O})$ peaks, and two $\mathrm{C}-\mathrm{H}$ stretching peaks along with spectra of
$1720 \mathrm{~cm}^{-1}, 1410 \mathrm{~cm}^{-1}$, and $1340 \mathrm{~cm}^{-1}$, respectively. It represents that the carbon content decreases and the oxygen content increases on the surface. The relative intensity of absorption peaks at $1720 \mathrm{~cm}^{-1}$ and $1340 \mathrm{~cm}^{-1}$ is also enhanced, suggesting the increase in the aldehyde, ketones, and aromatic groups on the surface [27]. During this case, a large amount of oxygen polar functional groups is introduced into the surface of plasma-treated PET films. This is responsible for improving wettability and changing the chemical composition of the surface [28].

\section{Conclusions}

The atmospheric-pressure argon plasma jet has been produced and characterized by electrical and optical methods. Electron density $\left(n_{\mathrm{e}}\right)$ and electron temperature $\left(T_{\mathrm{e}}\right)$ were found to be of the order of $10^{16} \mathrm{~cm}^{-3}$ and $0.551 \mathrm{eV}$, respectively, using the intensity ratio method. Similarly, electron density $\left(n_{\mathrm{e}}\right)$ was found to be of the order of $10^{15} \mathrm{~cm}^{-3}$ using an electrical method. Treatment of PET using the atmospheric-pressure plasma jet resulted in an improvement in hydrophilicity. It is mainly due to the increase in the polar component of the surface free energy after plasma jet treatment which indicates the formation of polar functional groups on the surface. The improvement of the wettability of PET strongly depends on the treatment time. Results showed that there is a significant reduction in the water contact angle on the polymer surface after plasma jet treatment with a consequent increase in its surface free energy. SEM and AFM images of the control and treated samples clearly indicated that the plasma treatment produces a significant increase in the roughness of the film. AFM can show the 3D pore structures of the sample and can detect the pores at the nanoscale which is beyond the ability of many conventional methods. Characterization of PET done by FTIR analysis showed adhesion of oxygen polar functional groups and stretching of $\mathrm{C}-\mathrm{H}$ bonds which can be correlated to improve wettability of the PET surface.

\section{Data Availability}

The data (figures and a table) and our corresponding research articles that support the findings of this study are available from the corresponding author upon request.

\section{Conflicts of Interest}

The authors declare that there is no conflict of interest regarding the publication of this article.

\section{Acknowledgments}

The authors would like to thank Prof. Dr. Gang Qin for his valuable help and support in the characterization of the discharge. The corresponding author was supported by the Nepal Academy of Science and Technology (NAST), Nepal, providing a Ph.D. fellowship through Grant No. 11/073/074. The authors would like to acknowledge Kathmandu University Plasma Physics Laboratory and University Grant Commission (UGC), Nepal, for their invaluable help 
and support. The authors would like to thank Prof. Andrzej Huczko from the University of Warsaw, Poland, for the SEM and AFM analysis of the polymer samples. Furthermore, we are also grateful to the International Conference on Nanoscience and High Energy Physics (ICNHEP), held at Kathmandu, Nepal, dated Feb 4-6, 2019, for providing us a platform to present preliminary results of our research work as a poster.

\section{References}

[1] M. Konuma, Film deposition by plasma techniques, vol. 10 of Springer Series on Atomic, Optical, and Plasma Physics, , Springer-Berlin, 1992.

[2] J. R. Roth, Industrial Plasma Engineering vol. 2: "Application to non-thermal plasma processing", IOP, Bristol and Philadelphia, 2001.

[3] D. P. Subedi, R. B. Tyata, R. Shrestha, and C. S. Wong, "An experimental study of atmospheric pressure dielectric barrier discharge (DBD) in argon," AIP Conference Proceedings, vol. 1588, no. 1, pp. 103-108, 2014.

[4] Z. Fang, J. Yang, Y. Liu, T. Shao, and C. Zhang, "Surface treatment of polyethylene terephthalate to improving hydrophilicity using atmospheric pressure plasma jet," IEEE Transactions on Plasma Science, vol. 41, no. 6, pp. 1627-1634, 2013.

[5] F. F. Chen, "Electric probes," in Plasma Diagnostic Techniques, J. D. Evans, W. Zawalski, R. H. Huddlestone, and S. L. Leornard, Eds., Academic Press, 1965.

[6] K. A. Vijayalakshmi, M. Mekala, C. P. Yoganand, and K. Navaneetha Pandiyaraj, "Studies on modification of surface properties in polycarbonate (PC) film induced by DC glow discharge plasma," International Journal of Polymer Science, vol. 2011, Article ID 426057, 7 pages, 2011.

[7] H. B. Baniya, R. Shrestha, A. Shrestha et al., "Surface modification of polycarbonate by atmospheric pressure argon/air plasma jet," Journal of Science, Engineering and Technology, vol. 10, no. 2, 2014

[8] K. Friedrich, "Polymer composites for tribological applications," Advanced Industrial and Engineering Polymer Research, vol. 1, no. 1, pp. 3-39, 2018.

[9] D. Hegemann, H. Brunner, and C. Oehr, "Plasma treatment of polymers for surface and adhesion improvement," Nuclear Instruments and Methods in Physics Research Section B: Beam Interactions with Materials and Atoms, vol. 208, pp. 281-286, 2003.

[10] R. T. Shrestha, An experimental study of atmospheric pressure plasma jet and its applications, $\mathrm{PhD}$ thesis, Department of Natural Sciences, School of Science, Kathmandu University, Nepal, 2016.

[11] A. Sarani, A. Y. Nikiforov, N. de Geyter, R. Morent, and C. Leys, "Surface modification of polypropylene with an atmospheric pressure plasma jet sustained in argon and an argon/water vapour mixture," Applied Surface Science, vol. 257, no. 20, pp. 8737-8741, 2011.

[12] D. P. Subedi, D. K. Madhup, K. Adhikari, and U. M. Joshi, "Plasma treatment at low pressure for the enhancement of wettability of polycarbonate," Indian Journal of Pure and Applied Physics, vol. 46, pp. 540-544, 2008.

[13] R. Guragain, S. Gautam, R. Shrestha, and D. P. Subedi, "Surface modification of polycarbonate by treatment with $50 \mathrm{~Hz}$ dielectric barrier discharge at near atmospheric pressure,"
International Journal of Science and Research (IJSR), vol. 5, pp. 1468-1470, 2016.

[14] H. B. Baniya, S. Shrestha, and D. P. Subedi, "Effect of floating electrode on the length of the capacitively coupled atmospheric pressure plasma jet," International Journal of Engineering Research-Online; A Peer Reviewed International Journal, vol. 4, no. 1, 2016.

[15] A. A. Shah, F. Hasan, A. Hameed, and S. Ahmed, "Biological degradation of plastics: a comprehensive review," Biotechnology Advances, vol. 26, no. 3, pp. 246-265, 2008.

[16] X. Lu, M. Laroussi, and V. Puech, "On atmospheric-pressure non-equilibrium plasma jets and plasma bullets," Plasma Sources Science and Technology, vol. 21, no. 3, article 034005, 2012.

[17] K. K. Trusov, "Dynamics of multichannel and quasihomogeneous sliding discharge formation in rare gases," Journal of Physics D: Applied Physics, vol. 40, no. 3, pp. 786-794, 2007.

[18] C. S. Wong and M. Rattachat, Elements of Plasma Technology, Springer, Singapore, 2016.

[19] S. Forster, C. Mohr, and W. Viol, "Investigations of an atmospheric pressure plasma jet by optical emission spectroscopy," Surface and Coatings Technology, vol. 200, no. 1-4, pp. 827830, 2005.

[20] A. Kramida, Y. Ralchenko, J. Reader, and NIST ASD Team, "NIST Atomic Spectra Database," 2018, March 2019, https:// physics.nist.gov/asd.

[21] Y. Yuan and T. R. Lee, "Contact angle and wetting properties," in Surface Science Techniques, G. Bracco and B. Holst, Eds., vol. 51 of Springer Series in Surface Sciences, Springer, Berlin, Heidelberg, 2013.

[22] H. B. Baniya, R. P. Guragain, B. Baniya, G. Qin, and D. P. Subedi, "Improvement of hydrophilicity of polyamide using atmospheric pressure plasma jet," Bibechana, vol. 17, pp. 133-138, 2020.

[23] T. S. M. Mui, R. P. Mota, A. Quade, L. R. . O. Hein, and K. G. Kostov, "Uniform surface modification of polyethylene terephthalate (PET) by atmospheric pressure plasma jet with a horn-like nozzle," Surface and Coatings Technology, vol. 352, pp. 338-347, 2018.

[24] R. P. Guragain, S. Gautam, R. Shrestha, and D. P. Subedi, "Effect of plasma treatment on the surface of polyethylene terephthalate with $50 \mathrm{~Hz}$ dielectric barrier discharge at nearatmospheric pressure," International Journal of Recent Research and Review, vol. 9, no. 4, pp. 34-37, 2016.

[25] T. Furukawa, H. Sato, Y. Kita et al., "Molecular structure, crystallinity and morphology of polyethylene/polypropylene blends studied by Raman mapping, scanning electron microscopy, wide angle X-ray diffraction, and differential scanning calorimetry," Polymer Journal, vol. 38, no. 11, pp. 1127-1136, 2006.

[26] N. L. Singh, A. Qureshi, N. Shah et al., "Surface modification of polyethylene terephthalate by plasma treatment," Radiation Measurements, vol. 40, no. 2-6, pp. 746-749, 2005.

[27] D. L. Pavia, G. M. Lampman, G. S. Kriz, and J. R. Vyan, Introduction to Spectroscopy, Cengage Learning, Stamford, CT USA, 2015.

[28] N. De Geyter, R. Morent, and C. Leys, "Surface characterization of plasma-modified polyethylene by contact angle experiments and ATR-FTIR spectroscopy," Surface and Interface Analysis, vol. 40, no. 3-4, pp. 608-611, 2008. 